\title{
Assessment of Academic Programs' Quality from Student Perspective at Najran University
}

\author{
Rula Ali Wahsheh (Corresponding author) \\ Assist. Professor of Curriculum and Instruction, College of Education \\ Najran University, KSA
}

Received: January 31, 2017 Accepted: February 23, 2017 Published: March 7, 2017

doi:10.5296/ire.v5i1.10889 URL: http://dx.doi.org/10.5296/ire.v5i1.10889

\begin{abstract}
The current study aimed to identify the degree of assessing the quality of academic programs at Najran University from students' perspective. Descriptive and analytical approach was adopted. The study population consisted of all students of the Faculty of Education in Najran University in Saudi Arabia, numbered (1380) students. The participants (296) students randomly selected, the author used the questionnaire as the tool of the study. The results showed that means of the assessment of the domain of faculty members at Najran University from students' perspective was high. There are no statistically significant differences of the assessment of academic programs' quality at Najran University from students' perspective due to gender. Furthermore, there are statistically significant differences of the assessment of academic programs' quality at Najran University from students' perspective due to academic year and Grade Point Average (GPA).
\end{abstract}

Keywords: evaluation, quality, academic programs, Najran University

\section{Introduction}

The assessment of academic programs in any university is considered a method for providing optimal educational quality for students, and important component for developmental process, which contribute to achieving the Higher Education mission and objectives, handling the challenges and difficulties faced by these programs since the academic programs' quality is considered one of the most important goals that universities seek to achieve to secure academic services provided.

The aims of assessing the quality of academic programs are represented in providing data, information, and evidences according to which clear frameworks, foundations, principles and procedures are being built; taking suitable administrative decisions to enhance the academic 
programs which contribute to achieving the academic goals and fulfilling best educational practices. The objectives of assessing the academic programs are represented in the decisions of modifying and changing academic programs in order to enhance their quality and helping in the progress of academic programs and achieving students' interest should be will delivered. (Marianopolis College, 2010)

Cordray, Pion, Brandt, Molefe and Toby (2013) have indicated that the assessment of the quality of academic programs can be evaluated in the universities through identifying strengths and weaknesses in their academic performance, which give them the ability to make the modification, reformation, change, and development which based on accurate information, that can be collected from students' perspective about their satisfaction of the academic programs which are provided by the universities, including elements and dimension importantly the faculty members, the scientific curricula, and the associated services for programs in addition to the used educational methods, attachments, infrastructure, the extent of the use of the modern technological means, etc.

Also, the assessment of the quality of academic programs is dependent on collecting data from the students about academic programs goals offered to them, the curricula, academic results, the educational methods applied by the faculty members, then these data is being analyzed in order to improve the academic programs improving Its implementation mechanism, supporting its scientific content, its quality's degree, coverage, and its ability in steering students academically in addition to the different scientific life courses. The process of assessing the quality of academic programs consists of a group of procedures that are represented in putting assessing plans, learning about the best ways and methods to apply them, applying the plan, collecting data including revising and analyzing it, improving the academic programs to match students' requirements and needs; finally, evaluate the impact of the amendments which are made to the academic programs from the perspective of students (Cacrep, 2016).

The assessment of the quality of academic programs plays a vital role in providing the faculty members with modern educational methods, which could help the educational process to achieve its goals; as the assessment of the quality of academic programs makes a link between the students' real results of evaluation and their perspective in the academic programs in addition to the future possible goals for the programs, as the goals of most academic programs are represented in providing students with knowledge and skills in various fields academically or professionally (University of New Mexico, 2015).

\section{Theoretical Framework and Literature Review}

\subsection{Quality}

Raqad (2014) has defined quality as the degree of the product or serve's appropriateness for use, which means the ability of the product or serve to present the thing which the recipient need, the use's appropriateness dependents on five basic elements represented in: design quality, matching quality, that the item or the serve be available, the safety of accessing the good or serve, the validity of the product or service's performance, since quality is defined as 
the degree of performance excellence and its conformity with established standards through foundation's perspective or from recipient's perspective.

Schindler, Elvidge, Welzant and Crawford (2015) defined quality as a group of standards that help in achieving distinction and exclusivity, the quality is also based upon the processes of public accountability and the effective change procedures that based upon previous experiments, extensive experience, and distinguished skills, that in turn ensure continuity of performance processes, and achieving the hoped public goals. Quality is described to be meaningful, designed to improve the production, services, achieving the best expected results, providing all necessary requirements, and it is also exceptional as it makes sure that the products and offered services are distinctive, unique, and original.

The quality is represented in the degree of achieving the best of excellence in the services or products that lead to get the best results; this is by depending on the experience and capacity, putting clear plans, providing all required needs and requirements to achieve the achievements and the target goals, most notably the information, tools, modern means that based on information technology, in addition to the assessment of how to carry out performance (Matsudaira, 2016).

Weikart (2013) indicated that considering the importance of quality assessment and its effect in taking the appropriate reform procedures, helping in the achievements of development and improvement, through training and support using the modern technology, this requires the provision of data and information which can be used to achieve continuous improvement and promote progress on all levels; the assessment of quality is considered as one of the important procedures and strategies for reform, which can be taken by the decision makers in order to enhance the performance and achieving the public goals. Also, the quality assessment contributes to highlighting the strengths and develops them, exploring the gaps, and the weaknesses and tries to improve them.

The quality logic is presented in imposing the existence of standards associated with educational system components, inputs, outcomes; these standards are distinguished by the vision and philosophy that are adapted by the programs, management's standard, faculty members, educational policies and practices, self-assessment; as the indicators and standards aim to achieve the overall quality in education and help in its management, as there is no quality without standards and indicators, and looking for quality means looking for the indicators as well (El-Makaneen \& El- Samadi, 2016).

Rehman (2016) indicated that the quality assessment is also helping in enhancing the effectiveness of the performance, coordinating the use of resources, and providing opportunities for reform and adjustment procedure, and quality assessment also contributes to activating its strategies which ensure a high level of performance, this is because the concept of quality includes a group of standards which help in determining to what extent this product meets the service offered and the required needs.

\subsection{Academic Programs}

Academic programs are considered one of the important goals that the universities and higher 
education institutions are seeking to develop and improve, activating its role in the personality's refinement of students and help them in developing their knowledge and research skills, enable them to engage the academic and professional life successfully, which requires making clear plans; provide all requirements and needs of students, evaluate results and mechanisms of the workings of programs, develop programs' methods in order to be contemporary to the latest discoveries of science and use the modern information technology, which ensure the academic programs efficiency and effectiveness in providing satisfying academic results (Rehman, 2016).

Nemar (2015) indicated that the importance of the academic programs is represented in providing clear information to what the students expect to get and achieve, the achievements that will be achieved after the end of the academic programs on scientific and professional level, as the academic programs provide the required, modern knowledge and information to the students which improve the performance, this is because the academic programs are organized and coordinated to enrich the experience gained by the students in many fields and help them in choosing the specialization which they see to be appropriate for their goals, by providing a group of specialization that display the different learning curricula such as the developmental and administrative curricula, liberal arts, and science, etc.

The academic programs are effected by a group of pressures which the educational institution faced including the lack of financial support, increasing the enrollment rates, lake of employment opportunities after graduation, lack of readiness of graduates and the applicants to the field work, which requires coordination and cooperation between the decision makers of the academic programs, employers, companies, funders investors, in order to activate the role of the academic programs, modifying approaches to meet the academic and logistical requirements (Cross et al., 2017).

Harrigan and Hulbert (2011) indicated that the universities are assessing their academic programs continually, putting clear plans to improve and ensure the quality of academic programs that are presented to the students, this is by assessing the students' results and academic achievements which usually reflect program's effectiveness and students benefit of it that contributes to unifying the academic programs goals with the higher education institutions representing in a high level of academic production, achieving excellence and competitiveness on the local, regional, and global level, that requires academic programs have modern educational means based on technological development, practical and effective decisions, the involvement of students in the educational process, providing their requirements, and commitment to the quality standards.

The academic programs make a group of curricula which are designed and prepared according to the university's vision, mission, objectives, and contribute to providing graduates with scientific skills and experiences qualify them to work efficiently in the work field, so it requires higher education institutions and universities (Muhammed, 2015):

1- Developing an integrated plan for the academic program that includes defining goals, a description for the nature of the courses, and identifying of the components of the curriculum. 
2- Taking into the account the market's requirements in designing academic programs, which secure the external environment changes and continuous improvement requirements.

3- Making sure that the academic programs outcomes are compatible with international standards in the professional fields, which the student will work in after the graduation through assessing the performance of graduates in work field.

4- Allocating a faculty of postgraduate studies in educational institution and university.

5- Making sure that the level of the faculty members meets the teaching requirements in postgraduate studies' programs.

It seems that the assessment of academic programs principles are based on the work upon the adopted standards, focusing on the students, reliance on assessment of various kinds, and continuity in the development, commitment in achieving the quality and its requirements, constant revision, and continuous accountability (El-Makaneen \& El- Samadi, 2016).

\subsection{Degree of Students' Assessment of the Academic Programs Quality}

There are many dimensions that measure the quality of the academic programs but in this research only three dimensions which are discussed as follows:

\subsubsection{Faculty Members}

Zakri and Qablan (2015) indicated that the assessment of the faculty members is represented in Identifyingt he effectiveness of the teaching staff and its ability to achieve the academic programs' goals, the assessment of the faculty members includes the teaching commission quality in terms of experience and diversity of specializations and sufficient number. Now the assessment is considered as a tool to improve and develop the performance quality, identify weaknesses and find solutions to them, represent the development of the faculty members in educational practices such as professionalism, mastery of educational material, punctuality, positive personality, effective methods of teaching, the ability of interacting with students and psychological balance in the human relationships between all parties of educational process one of the important aspects that the universities are considered in assessing and improving in order to enhance the performance of their faculty members, this is due to the importance of the role of the faculty members in achieving academic goals for the higher education institutions, as the faculty members are considered as an essential means in the improvement and development of teaching and learning structure, which contributes to the development of performance standards and develop the course content.

The assessment of the faculty members contributed to providing accurate, detailed information about the requirements of the faculty members upon which the necessary procedures are taken to provide the required suitable number of them in various specializations, the assessment also helps in providing programs and mechanisms to professional development of the faculty members to achieve the university goals, and the assessment is also helping in setting conditions which the higher education institutions have to take them into consideration, which are described as follows (Muhammad, 2015): 
1- The university identifies its need of the faculty members based on its vision and goals.

2- Providing an appropriate number of the faculty member according to the required certificates and scientific titles.

3- Identifying the standards of choosing the faculty members in terms of (cognitive qualifications, teaching methods, and the use of educational technologies).

4- The university identifies committees to test the teaching validity of the faculty members who were brought to work.

5- Developing instructions and regulations for the work load of faculty members according to their scientific degrees.

6- Developing accurate standards for assessing faculty members' performance in the domains of (teaching, depth of knowledge in the jurisdiction, the use of teaching methods and techniques, scientific research, authorship, translation, publishing, and community serve.)

7- The university provides efficient programs for the development of the faculty members in the professional and cognitive aspects.

8- The educational organization allocates prizes for the innovators in the domain of teaching and distinctive scientific research in accordance with vision and mission of the educational organization.

\subsubsection{Courses}

Tam (2014) indicated that the universities seek to develop the methods of quality assessment in order to improve the academic programs quality that are offered to the students, through continuous modifications and updates to the curricula and courses, the assessment of courses' quality is considered one of the important dimensions of the academic programs' quality, which their impacts are positively reflected on achieving a high level of advantage for academic programs, a successful product of academic students on all scientific and professional levels, as the assessment of the courses is presented in making a critical revision which designed to make adjustments and improvements to become more suitable for students' scientific requirements and needs that qualify them professionally, and moving them from the theoretical side to the practical side, which ensure the effectiveness, efficiency, and ability of the courses to prepare students with scientific high-quality competencies.

The assessment of the courses is one of the important elements which help the higher education institutions and universities to achieve satisfaction to the students from the academic programs' services, the importance of the assessment of courses quality can be explained in the following points (Raqad, 2014):

1- Developing the courses by identifying education strategy, focus on the existing internal relations between the different educational system levels and their environments; and working on the modernization and renewal of the scientific and practical aspects of the courses.

2- The assessment helps in preparing appropriate courses that can match the current situation in the light of drawn strategies include teaching methods, styles, means, and faculty members' efficiency. 
3- Developing plans to facilitate the process of implementation, financing, and changing the courses to suit the scientific and educational goals.

4- Identifying the appropriateness of the courses for the job market and professional environment's requirements.

5- Identifying the extent of the courses' ability to develop the critical scientific thinking, and helping students to solve their problems.

6- Identifying the courses' vocabulary available to develop the spirit of loyalty and belonging to the homeland.

\subsection{Provided Services}

The assessment of the quality services that the universities provided to the students in the academic programs is one of the most important goals that the universities seek to improve and develop because of its importance and necessity to enhance the goals of the academic programs, in addition to the assessment of the quality of the offered services ensures the effectiveness and program's efficiency, which consequently led to the development of academic students' abilities, aims to improve the performance and quality of the services that are provided to students, including liberalities, transportations, food, health, etc.; which supports students' learning and directs their attention to focus on learning and creativity, the goal of the offered services' assessment is representing in identifying the weaknesses, the attempt to address them, eliminating them, services' development, presented in a comfortable distinctive way, and by using the modern technological means (Alhabeeb, 2015).

Chalabi (2011) indicated that one of the most important issues that must be addressed when assessing the offered academic services are the following:

1- Providing appropriate classrooms equipped with the modern necessary equipment.

2- Providing appropriate offices for the faculty members.

3- Providing a specialized psychological counseling.

The importance of assessing the quality of the academic services which are offered for students in Identifying the degree of their satisfaction, conviction of the services and the university environment, its ability to provide their needs and meet their demands on the academic, practical, and psychological level, as the academic services should be like what the students' needs including the type and educational services' form which they will have in the university as the students' satisfactory about the academic services is considered one of the most important factors of assessing its development and academic growth, this also reflects the university's level and the level of the services which it presents, the standards of students' satisfaction about the academic services differ from one university to another; therefore, the university's care about assessing the quality of academic services helps in Identifying the extent of students' recognition to the university's offered services, and this gives it the opportunity to make the appropriate decisions to close the gap between the students' recognition of the quality's services and the real services (Hamdan, 2012).

Hamdan (2012) aimed to clarify the educational services' effect on the satisfaction of students in the Applied Science Private University. The study was made in Hashemite Kingdom of 
Jordan, it used analytical descriptive approach, as the sample consists of (433) students from various specializations. The study's results concluded that there is an effect of a statistically significant for educational serve's quality and the satisfaction of the Applied Science Private University students, the study recommended the importance of continuity of universities by confirming on the commitment, continuous development for the educational plan and improving the academic programs in the university to increase its educational processes' quality.

The study of El-Howaid (2013) aimed to identify the degree of the assessment of faculty member's performance contribution in increasing university education's quality. The study had been held in the Kingdom of Saudi Arabia, it used analytical descriptive approach, as the sample is consisted of 146 faculty members, and 264 female students. The study's results show that the assessment of the performance of the faculty members contributes to increasing the quality of the university education in Umm Al-Qura University as it affects the female students positively, develops the performance of the faculty members, develops the educational curricula, activates the teaching and learning sources. The study recommends the important of assessing faculty member's performance, using various methods for the process of assessment, in addition to emphasizing on building a model to assess the performance of the faculty members, which helps in increasing the quality of university education.

Salman (2013) aimed to measure the quality of the university services as perceived by the students of A-Aqsa University in Gaza by using the serve's quality measure or actual performance. The study was held in Gaza, it used the analytic descriptive approach, as the sample consisted of (380) male and female students and the measure had been handled with statistical means. The results showed that the quality of university services as perceived by the students of Al-Aqsa University among the week and medium in most of the dimensions' measure, there were statistically differences attributed to gender between males and females; and in favor of females in the level of the perceived university's services quality in all dimensions.

Novodvorsky (2015) aimed to review and assess the academic programs through the assessment of the faculty members, academic the results of the students, the curricula activities, and data analysis. The study was held in the state of Arizona, in the United States; it used the analytic approach, the analysis results had found that the academic outcomes are high level; this is due to the experiences of the faculty members, the quality of the offered curricula in the academic programs, and the study results showed that the assessment of academic programs contributes to improving their quality and effectiveness. The goal of Alhabeeb's (2015) study is measuring the level of quality serve offered to students at the college of education at King Saud University, specifically the gap between students' perceptions and expectations of the quality of the offered serve. The study was held in the Kingdom of Saudi Arabia, and used the analytical descriptive approach as the sample consisted of 199 males and females students of the college of education, the results showed that the services' quality was at a high level and the students' perceptions were positive as they exceeded the level of students' expectations, as the collage of Education offers all the services which the students need and with high quality. 
Zakri and Qublan (2015) aimed to investigate the attitudes of faculty members at Najran University towards students' assessment for their teaching performance and Identifying the level of the quality of faculty members' performance quality. This study is held in Najran in the Kingdom of Saudi Arabia, it used the analytic descriptive approach and the sample of the study consisted of (184) faculty members from Najran University. The result indicated that the attitudes of faculty members toward students 'assessment for their teaching performance were medium. In addition, they showed statistically significant differences in the attitudes of faculty members toward students' assessment for their teaching performance attributed to gender, teaching experiences, and the type of college. The study refers to the importance of diversity in the ways and methods of assessing the faculty members' performance in Najran University, not to be limited to the assessment of students to the teaching performance; beside the importance of holding seminars about the importance of assessing the quality of teaching performance of the faculty members to promote the educational process, the necessity of making lots of researches and studies which deals with assessing the quality of the performance of the faculty members.

\subsection{Commentary on the Literature Review}

The present study is distinguished than the previous researches and studies in handling the subject of academic programs' quality in Najran University from the students' perspective; this research has made use of the previous studies in forming the theoretical literature regarding research variables, in the composition of the methodology, and in the way of choosing sample and tools. This current research is matching with Novodvorsky's study, (2012) which indicated that academic programs' assessment contributes to improving their quality and effectiveness, and Hamdan's study (2012) which indicated that the commitment, the continuous development of the educational plan help in improving the academic programs, and increasing the quality of their educational processes.

\section{Statement of the Problem}

Due to the large number of students who want to join the Saudi universities, ensuring keeping up with the contemporary technological changes which refer to the importance of educational quality, and offering best services for students; it is important to consider education's quality and outcomes, which require a periodic assessment of the universities including organizational structures, behaviors, goals, and results and their evaluation. So the research problem is that the academic programs' goals in Najran University do not match with students' aspirations, insufficient to meet the actual needs of community and to prepare students well. Beside that the content of academic programs characterized by the multiplicity of the requirements related to the courses, which hinder students' educational process, as the teaching methods used with students do not encourage the critical scientific thinking.

Through the study problem the following questions emerged:

1- What is the degree of assessing the quality of academic programs?

2- Are there statistically significant differences at the level $(\alpha \leq 0.05)$ for the degree of assessing the quality of academic programs in Najran University from students' 
perspective due to variables (gender, academic year, and GPA)?

\subsection{Objectives}

Considering the importance of academic programs quality, the universities worked on the implementation of procedures and assessment processes to investigate the quality of academic programs' elements which are represented in the faculty members, courses, and the services which are offered to the students; that contribute to achieving practical and educational goals, the improvement of academic programs' quality and upgrading to distinctive performance for universities and higher education institutions, hence this research seeks to identify the degree of assessing the quality of academic programs in Najran University from students' perspective.

\subsection{Significance}

This research will add new theoretical literature for assessing the quality of academic programs.

1- Enrich the public Arabic library with this literature.

2- It is hoped that the research presents a clear vision for the officials about the degree of assessing the quality of academic programs, the possibility of applying, and making use of them in the field.

3- It is hoped for the research to be the core of other similar researches and studies and to be used as a reference for them.

\subsection{Study Terms}

Quality: the quality is defined as one of the works' strategies and academic researches' elements through which we can achieve excellence, exclusivity, goals, and ensure continuity (Schindler et al., 2015). Procedurally quality is defined as one of works' strategies which enable Najran University to achieve excellence in academic programs.

Wiliam (2013) indicated that assessment is defined as a group of criteria that measure the degree of quality or efficiency or excellence, and other various fields. It aims to reach clear results to help achieving the goals which the evaluation has been made for it, and there are several types of evaluation like qualitative and quantitative evaluation. Procedurally, evaluation is defined as a group of processes representing in analysis, processing, results, and feedback which carried out by Najran University to measure the level of the quality and reliability of academic programs from students' perspective.

Academic programs: can be defined as the optional courses or curricula that the students study to get a graduate degree either from universities or community colleges and other institutions of higher education; all students are subjected for a specific period which ends with getting a certificate enables them to get into the job market and career development (Burd et al., 2015). Procedurally they are defined as a group of courses and curricula that are chosen by Najran University students according to their majors. 


\subsection{Limitations}

The study is limited to the students in Najran University in the kingdom of Saudi Arabia in the first semester for the academic year (2016-2017).

\subsection{Population and Sample}

The population consists of all students of the Collage of Education in Najran University in the Kingdom of Saudi Arabia, totaling (1380) male and female students. A random sample has been selected to represent the study population, (300) questionnaires have been distributed over the male and female students, (298) questionnaires were getting back, (2) had been excluded as they weren't valid for analysis, the number of a sample is (296) male and female students, this is according to the table (BARTLET); below is a description of the study sample.

Table (1). Study sample characteristics

\begin{tabular}{cccc}
\hline Variable & Group & Frequency & Percentage \\
\hline \multirow{3}{*}{ Gender } & Female & 228 & $77 \%$ \\
& Male & 68 & $23 \%$ \\
& Total & 296 & $100 \%$ \\
\hline \multirow{4}{*}{ Academic } & $1^{\text {st }}$ & 121 & $40.9 \%$ \\
year & $2^{\text {nd }}$ & 69 & $23.3 \%$ \\
& $3^{\text {rd }}$ & 53 & $17.9 \%$ \\
& $4^{\text {th }}$ & 53 & $17.9 \%$ \\
GPA & Total & 296 & $100 \%$ \\
\hline & Pass & 56 & $18.9 \%$ \\
& Good & 143 & $48.3 \%$ \\
& Very good & 63 & $21.3 \%$ \\
& Excellent & 34 & $11.5 \%$ \\
& Total & 296 & $100 \%$ \\
\hline
\end{tabular}

Table (1) indicates the percentage of the males in the study-sample is (77\%) and the females' is $(23 \%)$. The percentage of $1^{\text {st }}$ academic year is $(40.9 \%), 2^{\text {nd }}$ year is $(23.3 \%), 3^{\text {rd }}$ year is $(17.9 \%)$, and $4^{\text {th }}$ year is $(17.9 \%)$ in the study-sample. The percentage of the students with GPA pass is $(18.9 \%)$, good is $(48.3 \%)$, very good $(21.3 \%)$, and excellent $(11.5 \%)$ in the study sample. In examining the results referred in table (1) regarding demographic characteristics of the study-sample, it can be concluded that these results as a whole provide an indication which can be relied upon concerning the eligibility of sample's persons to answer the questions in the questionnaire, and then rely on their answers mainly to extract the targeted results from the study.

\subsection{Study Tool}

The questionnaire was held to measure the degree of academic programs' assessment in Najran University from students' perspective; the questionnaire consisted of two parts: the first part regards the basic information (demographics) of the sample, represented in (gender, academic year, GPA), while the second part of the questionnaire consists of three domains:

- The first domain is the faculty members, including (12) paragraphs (1-12). 
- The second domain is the courses, including (12) paragraphs (13-24).

- The third domain is the offered services, including (13) paragraphs (25-37).

Each paragraph from the study dimensions of the questionnaire is given degrees to be treated statistically as follow: strongly agree (5), agree (4), neutral (3), disagree (2), and strongly disagree (1).

The following scale is used in data analysis:

Maximum of the scale - the minimum scale $\backslash$ categories number $=$

$5-1 \backslash 3=4 \backslash 3=1.33$ the length of the category based on this the categories are as follows:

From (1-2.33) low.

From (2.34-3.67) medium.

From (3.68-5) high.

The grades were divided into three levels as follows:

- Low level if the means ranged between (1-2.33).

- Medium level if the means ranged between (2.34-0.673).

- High level if the means ranged between (3.68-5).

\section{Validity}

It was verified through presenting the questionnaire to a group of reviewers including (10) professors from faculty members in this field, the opinions and comments of the reviewers are taken into consideration through adding, deleting, and modifying some paragraphs to reach the final draft of the questionnaire.

\section{Reliability}

For making sure that the questionnaire measures the intended factors, verifying its reliability, the author had made a test to the internal consistency of the scale's paragraphs through the coefficient (Cronbach Alpha), this is because Cronbach Alpha's test depends on the consistency of individual performance from one paragraph to another, this refers to the strong link and cohesion between scale's paragraphs, in addition to the reliability.

Table (2). Reliability coefficients of the degree of assessing the quality of academic programs in Najran University from students' perspective

\begin{tabular}{ccc}
\hline No. & Domain & Cronbach Alpha \\
\hline 1 & Faculty members & 0.874 \\
2 & Courses & 0.846 \\
3 & Academic services provided & 0.878 \\
& Total & 0.932 \\
\hline
\end{tabular}

In table (2), reliability coefficients indicate that the tool has a high reliability coefficient and the tool's ability to achieve study goals in general. As the table indicates that the highest reliability coefficient for the questionnaire's dimension reached to (0.878) and the lowest value of reliability was (0.846). That indicates the possibility of results' reliability which the 
application of the questionnaire will show as the reliability coefficient values (Alpha $>0.60$ ) are appropriate for applying the questionnaire.

\section{Results}

The first question: what is the degree of assessing the quality of the academic programs in Najran University from students' perspective?

To answer this question the arithmetic means and standard deviations for the domains of the academic programs quality in Najran University have been calculated in total and for each domain of the study tool's domains; as shown in table (3).

Table (3). The arithmetic means, standards deviations, and the ranks for the domains of the academic programs quality in Najran University in descending order

\begin{tabular}{cccccc}
\hline No. & Domain & Arithmetic mean & standard deviation & Rank & Assessment degree \\
\hline 1 & Faculty members & 3.81 & 0.67 & 1 & High \\
2 & Courses & 3.62 & 0.63 & 3 & Medium \\
3 & Academic services provided & 3.74 & 0.67 & 2 & High \\
& Total & 3.72 & 0.55 & & High \\
\hline
\end{tabular}

Table (3) indicates that the Assessment degree for the total degree of the study tool was a high degree, as the arithmetic mean (3.72) with a standard deviation (0.55), all tool's domains achieve medium and high degree, as the domain of "the faculty members" comes in the first rank, with an arithmetic mean (3.81) and a standard deviation (0.67), in the last rank the domain of "courses) with an arithmetic mean (3.62) and a standard deviation (0.63).

Faculty members' domain:

The arithmetic means, standards deviations, and the ranks of faculty members' domain; as shown in table (4).

Table (4). The arithmetic means, standard deviations, and the ranks of faculty members' domain in descending order

\begin{tabular}{|c|c|c|c|c|c|}
\hline No. & Domain & $\begin{array}{l}\text { Arithmetic } \\
\text { mean }\end{array}$ & $\begin{array}{c}\text { Standard } \\
\text { deviations }\end{array}$ & Rank & $\begin{array}{c}\text { Assessment } \\
\text { degree }\end{array}$ \\
\hline 8 & Faculty members accept the constructive criticism. & 4.07 & 0.93 & 1 & High \\
\hline 7 & $\begin{array}{l}\text { Faculty members take into consideration the logic } \\
\text { organized hierarchy. }\end{array}$ & 4.05 & 0.92 & 2 & High \\
\hline 6 & $\begin{array}{l}\text { The teaching strategies of the faculty members are } \\
\text { clear. }\end{array}$ & 3.97 & 1.05 & 3 & High \\
\hline 1 & Faculty members treat the students fairly. & 3.96 & 0.88 & 4 & High \\
\hline 5 & $\begin{array}{l}\text { Faculty members adhere to the specific time for } \\
\text { the lecture. }\end{array}$ & 3.89 & 1.04 & 5 & High \\
\hline 3 & $\begin{array}{l}\text { Faculty members seek to develop the skills of } \\
\text { creativity and innovation. }\end{array}$ & 3.81 & 1.05 & 6 & High \\
\hline 12 & $\begin{array}{l}\text { Faculty members use suspense element to increase } \\
\text { learning motivation. }\end{array}$ & 3.79 & 1.09 & 7 & High \\
\hline 4 & $\begin{array}{l}\text { The faculty members differ in the tests of } \\
\text { assessment. }\end{array}$ & 3.74 & 0.99 & 8 & High \\
\hline
\end{tabular}


10 Faculty members specify part of the marks on the activities and writing scientific research.

Faculty members encourage students to write the

9 researches and reports which serve the educational process.

Faculty members allow suggestions and different opinions.

11 Faculty members connect the course with experiments and students' personal experience.

Total
3.72

3.6

1.03

9

High

1.03

10

Medium
3.57

1.02

3.54

1.27

0.67

Medium

Medium

3.81

High

Table (4) indicates that the degree of assessing the quality of faculty members' domain was high, as the arithmetic mean was (3.81) with standard deviation (0.67), this domain's paragraphs achieve middle and high degree, as the arithmetic means ranging from (3.544.07), paragraph (8) comes in the first rank which indicates that "the faculty members accept the constructive criticism", by a arithmetic means (4.07), standard deviation (0.93), and a high Assessment degree, paragraph (11) at the last rank, which indicates that " Faculty members connect the course with experiments and students' personal experience", by a arithmetic means (3.54), standard deviation (1.27), and medium degree.

\section{Courses domain}

The arithmetic means, standard deviations, ranks of courses have been calculated; as shown in table (5).

Table (5). The arithmetic means, standard deviations, ranks of courses domain in descending order

\begin{tabular}{|c|c|c|c|c|c|}
\hline No. & Domain & $\begin{array}{l}\text { arithmetic } \\
\text { mean }\end{array}$ & $\begin{array}{c}\text { Standard } \\
\text { deviations }\end{array}$ & Rank & $\begin{array}{c}\text { Assessment } \\
\text { degree }\end{array}$ \\
\hline 17 & Enhance the courses values and skills. & 3.86 & 1.06 & 1 & High \\
\hline 14 & $\begin{array}{l}\text { The amount of courses is compatible with the } \\
\text { number of hours scheduled for the course in the } \\
\text { semester. }\end{array}$ & 3.83 & 0.99 & 2 & High \\
\hline 13 & $\begin{array}{l}\text { The courses related to the specialization are } \\
\text { different and cannot be understood. }\end{array}$ & 3.76 & 1.05 & 3 & High \\
\hline 18 & The courses develop communication skills. & 3.71 & 1.01 & 4 & High \\
\hline 22 & $\begin{array}{l}\text { The courses enhance and develop the scientific } \\
\text { concepts. }\end{array}$ & 3.68 & 1.03 & 5 & High \\
\hline 19 & $\begin{array}{l}\text { The courses take the differences in mental levels } \\
\text { into consideration. }\end{array}$ & 3.57 & 1.04 & 6 & Medium \\
\hline 20 & $\begin{array}{l}\text { The courses seem to be unchangeable and } \\
\text { undeveloped. }\end{array}$ & 3.55 & 1.08 & 7 & Medium \\
\hline 21 & The courses include elements of suspense and fun. & 3.53 & 1.04 & 8 & Medium \\
\hline 23 & The courses develop analysis and inquiry skills. & 3.53 & 1.04 & 9 & Medium \\
\hline 24 & The courses meet job market's requirements. & 3.52 & 1.08 & 10 & Medium \\
\hline 15 & The courses stimulate self-learning. & 3.49 & 1.11 & 11 & Medium \\
\hline \multirow[t]{2}{*}{16} & $\begin{array}{l}\text { The courses take the sequencing and the logic } \\
\text { coherence of information into consideration. }\end{array}$ & 3.39 & 0.98 & 12 & Medium \\
\hline & Total & 3.62 & 0.63 & & Medium \\
\hline
\end{tabular}

Table (5) indicates that the Assessment degree of courses domain was medium, as the arithmetic mean was (3.62) and standard deviation was (0.63), the domain's paragraphs achieved medium and high degree, as the arithmetic means mean from (3.39 -3.86); 
paragraph (17) comes in the first rank which indicates that the " courses enhance values and skills", by arithmetic mean (4.86) and standard deviation (1.06) and a high Assessment degree; in the last rank comes paragraph (16) which indicates that "the courses take the sequencing and the logic coherence of information into consideration" with arithmetic mean (3.39) and standard deviation (0.98) and a medium Assessment degree.

\section{Provided services}

The arithmetic means, standard deviations, and position for the provided serve domain have been calculated, as shown in table (6).

Table (6). The arithmetic means, standard deviations, and ranks of the provided serve domain in descending order

\begin{tabular}{|c|c|c|c|c|c|}
\hline No. & Domain & $\begin{array}{l}\text { arithmetic } \\
\text { mean }\end{array}$ & $\begin{array}{c}\text { Standard } \\
\text { deviations }\end{array}$ & Rank & $\begin{array}{c}\text { Assessment } \\
\text { degree }\end{array}$ \\
\hline 36 & $\begin{array}{l}\text { The universities provide the required services for } \\
\text { students with special needs to help them in } \\
\text { academic interaction. }\end{array}$ & 3.93 & 1.07 & 1 & High \\
\hline 27 & $\begin{array}{l}\text { The university contains libraries and laboratories to } \\
\text { support the educational process. }\end{array}$ & 3.86 & 1.04 & 2 & High \\
\hline 28 & $\begin{array}{l}\text { The university is committed to achieve security and } \\
\text { safety standards in its facilities. }\end{array}$ & 3.83 & 1 & 3 & High \\
\hline 31 & $\begin{array}{l}\text { The universities contain units to develop creativity } \\
\text { and innovation ability. }\end{array}$ & 3.81 & 1.03 & 4 & High \\
\hline 35 & $\begin{array}{l}\text { The university keeps up with employing modern } \\
\text { technology in educational processes. }\end{array}$ & 3.77 & 1.06 & 5 & High \\
\hline 32 & $\begin{array}{l}\text { The classrooms are equipped with the assistive } \\
\text { means and devices for learning. }\end{array}$ & 3.75 & 0.98 & 6 & High \\
\hline 37 & $\begin{array}{l}\text { University facilities are clean and organized to } \\
\text { serve the educational process. }\end{array}$ & 3.72 & 1.16 & 7 & High \\
\hline 33 & $\begin{array}{l}\text { The university encourages students through } \\
\text { material and moral incentives. }\end{array}$ & 3.71 & 1.1 & 8 & High \\
\hline 25 & $\begin{array}{l}\text { The universities have guidance's sections, } \\
\text { psychological and educational guidance. }\end{array}$ & 3.7 & 0.99 & 9 & High \\
\hline 29 & $\begin{array}{l}\text { Students' procedures of registration in courses are } \\
\text { easily and conveniently. }\end{array}$ & 3.69 & 1.02 & 10 & High \\
\hline 34 & $\begin{array}{l}\text { Universities distributed brochures and guides for } \\
\text { the educational process. }\end{array}$ & 3.67 & 1.06 & 11 & Medium \\
\hline 26 & $\begin{array}{l}\text { University concerns with doing extracurricular } \\
\text { activities for students. }\end{array}$ & 3.61 & 1.06 & 12 & Medium \\
\hline \multirow[t]{2}{*}{30} & $\begin{array}{l}\text { Scientific and computational laboratories in the } \\
\text { university fit students' number. }\end{array}$ & 3.6 & 1.05 & 13 & Medium \\
\hline & Total & 3.74 & 0.67 & & High \\
\hline
\end{tabular}

Table (6) indicates that the Assessment degree of provided services' domain was high, as the arithmetic means was (3.62) and standard deviation (0.63); this domain's paragraphs achieved medium and high degree, as the as the arithmetic means mean (3.60-3.93), in the last position comes paragraph number (36) which indicate " The universities provide the required services for students with special needs to help them in academic interaction", the arithmetic mean is (3.93) and standard deviation is ( 1.07) and a high Assessment degree; in the last rank comes paragraph (30) which indicates that "scientific and computational laboratories in the university fit students' density", the arithmetic mean is (3.60), standard deviation is $(0,05)$, 
and medium Assessment degree.

The second question: Are there statistically significant differences at significance level $(\alpha \leq$ $0.05)$ for the degree of assessing the quality of academic programs in Najran University from students' perspective due to (gender, academic year, and GPA)?

\section{Gender:}

In order to answer this question, value ( $\mathrm{T}$ ) the mean to the assessment degrees of the academic programs' quality has been extracted in Najran University, according to the gender (female, male); value (T) the mean of two categories (females, males), and the results were as follows:

Table (7). Arithmetic means, standard deviations, and value (T) of the answers of the studysample members: males and females.

\begin{tabular}{ccccc}
\hline Domain & Group & Arithmetic mean & T-Value & $\begin{array}{c}\text { significance } \\
\text { level }\end{array}$ \\
\hline \multirow{2}{*}{ Faculty members } & Females & 3.81 & .144 & .886 \\
& Males & 3.80 & & .168 \\
Courses & Females & 3.59 & 1.386 & .138 \\
\hline \multirow{2}{*}{ Provided services } & Males & 3.71 & & \multirow{2}{*}{1.492} \\
\hline
\end{tabular}

The results mentioned in table (7) indicate that there is not any statistical significant difference in the significance level $(\alpha \leq 0.05)$ regarding arithmetic means in the answers of the two categories members in all study domains as it was higher than (0.05), a non-statistical significant.

\section{Academic year:}

To answer this question we use one-way analysis of variance (ANOVA) in studying the means of the assessment of the academic programs' quality in Najran University according to the academic year. Table (8) indicates the results:

Table (8). One-way analysis of variance of the differences in study-sample answers in the study of means of assessing academic programs' quality in Najran University according to the academic year

\begin{tabular}{|c|c|c|c|c|c|c|}
\hline Domain & $\begin{array}{c}\text { Variation } \\
\text { source } \\
\end{array}$ & $\begin{array}{l}\text { Sum of } \\
\text { Squares }\end{array}$ & $\begin{array}{c}\text { Freedom } \\
\text { degree }\end{array}$ & $\begin{array}{l}\text { Mean of } \\
\text { Squares }\end{array}$ & $\mathrm{F}$ & $\begin{array}{c}\text { Significance } \\
\text { level }\end{array}$ \\
\hline \multirow{3}{*}{$\begin{array}{l}\text { Faculty } \\
\text { members }\end{array}$} & $\begin{array}{c}\text { Between } \\
\text { groups }\end{array}$ & 4.401 & 3 & 1.467 & \multirow[t]{3}{*}{3.387} & \multirow[t]{3}{*}{.019} \\
\hline & within groups & 126.503 & 292 & .433 & & \\
\hline & Total & 130.904 & 295 & & & \\
\hline \multirow{3}{*}{ Courses } & $\begin{array}{l}\text { Between } \\
\text { groups }\end{array}$ & 9.629 & 3 & 3.210 & \multirow[t]{3}{*}{8.814} & \multirow[t]{3}{*}{.000} \\
\hline & within groups & 106.337 & 292 & .364 & & \\
\hline & Total & 115.966 & 295 & & & \\
\hline \multirow{2}{*}{$\begin{array}{l}\text { Provided } \\
\text { services }\end{array}$} & $\begin{array}{l}\text { Between } \\
\text { groups }\end{array}$ & 4.493 & 3 & 1.498 & \multirow[t]{2}{*}{3.448} & \multirow[t]{2}{*}{.017} \\
\hline & within groups & 126.833 & 292 & .434 & & \\
\hline
\end{tabular}




\section{Total \\ 131.326 \\ 295}

Table (8) indicates that there are statistical significant differences in the significance level $(\alpha$ $\leq 0.05)$ in the means of assessing academic programs' quality in Najran University according to the academic year; if there are differences lower than (0.05) in all domains and it is a statistic significant. In order to find the differences source the Scheffe' test for Posterior Comparisons has been made; table (9) indicates this:

Table (9). Posterior Comparisons on Scheffe's way in studying the means of assessing academic programs' quality in Najran University according to the academic year

\begin{tabular}{ccccccc}
\hline Domain & Year & Arithmetic mean & First & Second & Third & Fourth \\
\hline \multirow{5}{*}{ Faculty members } & First & 3.94 & & & & \\
& Second & 3.65 & $.29634^{*}$ & & & \\
& Third & 3.72 & .22202 & .07432 & & \\
& Fourth & 3.81 & .13397 & .16237 & .08805 & \\
\hline \multirow{5}{*}{ Courses } & First & 3.80 & & & & \\
& Second & 3.34 & $.46419^{*}$ & & & \\
& Third & 3.58 & .21857 & .24562 & & \\
& Fourth & 3.59 & .21571 & .24848 & .00286 & \\
Provided services & First & 3.86 & & & & \\
& Second & 3.55 & $.31854^{*}$ & & & \\
& Third & 3.75 & .11623 & .20231 & & \\
& Fourth & 3.72 & .14381 & .17473 & .02758 & \\
\hline
\end{tabular}

Table (9) indicates the values which show the variance and the categories with statistical significance, as the number which contain $\left(^{*}\right)$ refer to the differences between the intersecting categories according to the academic year; and know according to which category we consider the arithmetic mean, because the variances are for the higher arithmetic mean category and here the variances are for (First Year) category in all domains.

GPA:

To answer this question we use One-way analysis of variance (ANOVA) in studying the means of the assessment of the academic programs' quality in Najran University according to the GPA; table (10) indicates the results.

Table (10). One-way analysis of variance for the differences of the study-sample answers in studying the means of the assessment of the academic programs' quality in Najran University according to the GPA

\begin{tabular}{|c|c|c|c|c|c|c|}
\hline Domain & Variation source & $\begin{array}{l}\text { sum of } \\
\text { Squares }\end{array}$ & $\begin{array}{c}\text { Freedom } \\
\text { degree }\end{array}$ & $\begin{array}{l}\text { mean of } \\
\text { Squares }\end{array}$ & $\mathrm{F}$ & $\begin{array}{c}\text { Significance } \\
\text { level }\end{array}$ \\
\hline \multirow{3}{*}{$\begin{array}{l}\text { Faculty } \\
\text { members }\end{array}$} & Between groups & 4.387 & 3 & 1.462 & \multirow{3}{*}{3.375} & \multirow{3}{*}{.019} \\
\hline & within groups & 126.517 & 292 & .433 & & \\
\hline & Total & 130.904 & 295 & & & \\
\hline \multirow{3}{*}{ Courses } & Between groups & 4.555 & 3 & 1.518 & \multirow{3}{*}{3.979} & \multirow{3}{*}{.008} \\
\hline & within groups & 111.412 & 292 & .382 & & \\
\hline & Total & 115.966 & 295 & & & \\
\hline \multirow{3}{*}{$\begin{array}{l}\text { Provided } \\
\text { services }\end{array}$} & Between groups & 3.410 & 3 & 1.137 & \multirow{3}{*}{2.595} & \multirow{3}{*}{.053} \\
\hline & within groups & 127.915 & 292 & .438 & & \\
\hline & Total & 131.326 & 295 & & & \\
\hline
\end{tabular}


Table (10) indicates the differences in the statistically significant in significant level $(\alpha \leq$ $0.05)$ in the means of the assessment of the academic programs' quality in Najran University according to the GPA if the variances were lower than (0.05) in all domains and it is a statistically significant, except the domain of (provided services). To find the variances' source the Scheffe' test for Posterior Comparisons has been made; as shown in table (11):

Table (11). Posterior Comparisons on Scheffe's way in studying the means of assessing academic programs' quality in Najran University according to the GPA

\begin{tabular}{lllllll}
\hline Domain & GPA & Arithmetic mean & Pass & Good & Very good & Excellent \\
\hline \multirow{4}{*}{ Faculty members } & Pass & 4.02 & & & & \\
& Good & 3.71 & $.30813^{*}$ & & & \\
& Very good & 3.88 & .13808 & .17005 & & \\
& Excellent & 3.73 & .28955 & .01858 & .15147 & \\
Courses & Pass & 3.79 & & & & \\
& Good & 3.56 & .23480 & & & \\
& Very good & 3.71 & .08287 & .15193 & & \\
& Excellent & 3.39 & $.40480^{*}$ & .17000 & .32193 & \\
\hline
\end{tabular}

Table (11) indicates the values which show the variance and categories with statistical significant as the numbers with $(*)$ refer to the differences between the intersecting categories according to the GPA, in order to know to which category it belongs we have to look at the arithmetic mean, because the differences belong to the category with the higher arithmetic mean, here the differences belong to the category of (pass) in both domains.

\section{Discussion}

\subsection{Faculty Members'}

The results of the arithmetic means show that the degree of the assessment of faculty members' domain was high, as paragraph (8) which indicates that "the faculty members accept the constructive criticism", in the first rank, and this is because the students believe that the faculty members open the way in front of them to say their suggestions and multiple opinions, and accept the constructive criticism that services the educational process. This result is consistent with the results of the study Novodvorsky, (2015) which indicated that the academic outcomes are from high academic level. Paragraph (11) which indicates that "Faculty members connect the course with experiments and students' personal experience" comes in the last rank; these because the students believe that the faculty members connect the course with their experiences and experiments, through divide their marks on activities, writing research, and reports that serve the educational process.

\subsection{Courses}

The means' results indicate that the Assessment degree of the courses' domain was medium, as paragraph (17) indicates that "the courses enhance the values and skills", comes in the first position' this is because the students of Najran University believe that the courses enhance their scientific concepts and develop them because they include elements of fun and suspense, which make them flexible and learnable. Paragraph (16) which indicates that "The courses take the sequencing and the logic coherence of information into consideration," 
comes in the last rank because the students believe that the courses take the sequencing and the logic coherence of information into consideration a little bit; and it may also attribute to it considers a little bit the differences in mentality levels.

\subsection{Provided Services}

The means' results indicate that the Assessment degree of the provided services' domain was high, as paragraph (36) which indicates that" The universities provide the required services for students with special needs to help them in academic interaction," comes in the first rank; because students believe that the university is concerning with provide the required services for students with special needs to help them in academic interaction through providing guidance's sections, psychological and educational guidance, and achieve security and safety standards in its facilities. This result is consistent with with the study results of Hamdan, (2012) which indicate that there is a statistical significant impact for the educational services quality and students' satisfaction.

Paragraph (30) which indicates that "Scientific and computational laboratories in the university fit students' density." this is because the university knows the importance of providing the necessary requirements to achieve academic programs' quality through providing scientific laboratories fit students' density and their ability to make use of the technology in the educational processes.

Discussing the results regarding the second question: Are there statistically significant differences at significance level $(\alpha \leq 0.05)$ for the degree of assessing the quality of academic programs in Najran University from students' perspective due to demographic variables (gender, academic year, and GPA)?

\subsection{Gender:}

The results indicate that there are not any statistical significant differences in the Assessment degree of the academic programs' quality in Najran University of gender variable from students' perspective. This is because according to students the Assessment degree of the academic programs' quality is fixed and does not change according to the gender as it affects both genders, because both of females and males study the same courses and have the same faculty members.

This result is different from the results of Zakri and Qablan, (2015) study; which indicates that there are differences in the faculty members' approach towards the assessment of students' academic performance attributed to gender variable.

\subsection{Academic Year}

The results indicate that there are statistical significant differences in the Assessment degree of the academic programs' quality in Najran University of academic year variable from students' perspective. this also can be attributed that the study years affect students Assessment degree of the academic programs' quality; as the second-year students' perspectives of the academic programs' quality differ from the students of third and fourth year perspectives as whenever the study years increases their ability of assessment increase, 
this may be because they have studied more courses and pass lots of experiments in every academic year.

\subsection{GPA}

The results indicated that there are statistical significant differences in the degree of assessing the academic programs' quality in Najran University of GPA variable from students' perspective. This can be because the GPA affects the degree of assessing the academic programs in Najran University, as whenever the GPA increased, their ability of assessment increased, and vice versa; which is because the students with GPA excellent their perspective of the course is different from students with pass or good GPA.

\section{Recommendations}

1. The need of adhering to the plans and educational courses to improve academic programs to match with the modern development.

2. Providing scientific and computational laboratories fit students' density in the universities which support the educational process.

3. Conducting further studies on assessing academic programs' quality on populations other than the present population to get broader and deeper results.

\section{References}

Alhabeeb, A. (2015). The Quality Assessment of the Services Offered to the Students of the College of Education at King Saud University using (SERVQUAL) Method. Journal of Education and Practice, 6(3), 82-93.

Burd, G. (2015). Academic Program Review Procedure Manual 2015-2016.The University of Arizona, Tucson, AZ 85721.

CACREP (2016). Guiding Principles for Program Evaluation and Student Assessment Section 4 of the 2016 CACREP Standards. CACREP Standards, 1-8.

Chalabi, S. (2011). Ensure the quality and the accreditation for the academic programs in educational institutions (objectives, procedures, and results). Research presented to the conference of Universities Association of Lebanon in cooperation with the National Office of the European Tempus Program in the duration of (29-30) April 2011, Lebanon.

Cordray, D., Pion, G., Brandt, C., Molefe, A., \& Toby, M. (2013). The Impact of the Measures of Academic Progress (MAP) Program on Student Reading Achievement. National Center for Education Evaluation and Regional Assistance

Cross, T., Bazron, B., Dennis, K., \& Isaacs, M. (2017). Towards A Culturally Competent System of Care. Washington, DC: Georgetown University Child Development Center.

El- Makaneen, H., \& Alsamady, J. (2016). The assessment of private education programs in the early childhood in Jordan in the light of the global qualitative indicators. Journal of Educational Science, 43(2), 817- 836.

El-Howaid, N. (2013). The Assessment of Faculty Member's Performance Contribution in 
Increasing University Education Quality; unpublished MA thesis, Umm Al-Qura University in the Kingdom of Saudi Arabia.

Hamdan, K. (2012). The quality of the educational services and their impact on the students' satisfaction; an applied study on Applied Science Private University. Research presented to the Second International Arab Conference on Quality Assurance in Higher Education 917929.

Harrigan, P., \& Hulbert, B. (2011). How can marketing academics serve marketing practice? The new marketing DNA as a model for marketing education. Journal of marketing education, $33(3), 253-272$.

Marianopolis College. (2010). Institutional Policy on the Evaluation of Programs. Marianopolis College IPEP, 1-21.

Matsudaira, J. (2016). Defining and Measuring Institutional Quality in Higher Education. National Academies Press, 1-25.

Muhammed, Galal Abdel Allah (2015). The effect of quality standards upon applying total quality management: Analytical study for the survey of employees of Technical Institute in Sulaimani. Research presented to The Fifth International Arab Conference on Quality Assurance in Higher Education, 3-5/3/ 2015, University of Sharjah, United Arab Emirates.

Nemar, S. (2015). What factors will influence high school pupils in Lebanon when choosing a university?.A research thesis, Southern Cross University, Lismore, NSW.

Novodvorsky, I. (2015). Supporting and Evaluating Learning Outcomes Assessment Through Academic Program Reviews. Assessment Update, 4.

Raqad, S. (2014). The application of the quality assurance system in the Algerian higher education institutions: its prospects and obstacles a field study in the higher education of Algerian east. Unpublished PHD thesis, University of Setif, Algeria.

Rehman, S. (2016). Accrediting LIS Programs: Options and Opportunities. International Quality Assessment of LIS Education Programs, 1-15.

Salman, Muhammed Ibrahim (2013). the level of the University services' quality as perceived by the students of Al-Aqsa University in Gaza according to the measure of serve's quality. Journal of Al-Aqsa University (Series of Human Sciences) 71: 1-50.

Schindler, L., Puls-Elvidge, S., Welzant, H., \& Crawford, L. (2015). Definition of Quality in Higher Education: A Synthesis of the Literature. High. Learn. Res. Commun., 5(3), 3-13.

Tam, M. (2014). Outcomes-based approach to quality assessment and curriculum improvement in higher education. Research Gate Journal, 1-14.

University of New Mexico. (2015). Academic Program Assessment Manual. Retrieved from https://artsci.unm.edu/assessment/files/unm-assessment-handbook.pdf

Weikart, D. (2013). Summer Learning Program Quality Intervention. National Summer 
Learning Association.

Wiliam, D. (2013). Assessment: The Bridge between Teaching and Learning. Voices from the Middle, 21(2), 15-20.

Zakri, A., \& Qablan, Y. (2015). Attitudes of Faculty Members at Najran University towards Students' Assessment for Their Teaching Performance. Journal of Education and Practice, $6(35), 17-24$.

\section{Copyright Disclaimer}

Copyright reserved by the authors.

This article is an open-access article distributed under the terms and conditions of the Creative Commons Attribution license (http://creativecommons.org/licenses/by/3.0/). 